\title{
The Effect of Gender, Age and Cerebral Palsy Sub-Type on The Prevalence of Specific Gait Deviations in Cerebral Palsy Children
}

\author{
Tochukwu Nze Ugorji*, Patrick Ugochukwu Agbasi, Daniel Jovita Ada, Innocent Agbonika and Mirian \\ Onyekwusi
}

Department of Prosthetics and Orthotics, Federal University of Technology, Nigeria

Submission: June 7, 2019; Published: July 29, 2019

*Corresponding author: Tochukwu Nze Ugorji,Department of prosthetics and Orthotics, Federal University of Technology Owerri Nigeria

Abstract

Objective: to find out the effect of managerial protocols, age and gender on the prevalence of specific gait patterns among children suffering from cerebral palsy. It is expected that this study will help researchers and clinicians focus their efforts in areas that will enhance the general functioning and the gait efficiency of children suffering from cerebral palsy instead of incorporating excessive treatment options that might have little or no effect on the gait improvement of patients with cerebral palsy.

Method: a descriptive design was adopted to investigate the impact of effect of gender, age and cerebral palsy sub-type on the prevalence of specific gait patterns seen in cerebral palsy patients who were currently accessing treatments between (2005-2015) in the hospitals used and are within the age range of 4-20years.

Result: a total of one hundred and forty-two cerebral palsy patient's folders were reviewed from two hospitals. Necessary information obtained were ages, type of cerebral palsy and gender of the patient, also documented was noted gait deviations. The prevalence of 12 gait abnormalities were evaluated and compared based on sub-type (Hemiplegia, Diplegia and Quadriplegia), gender and age of the patient. Stiff knee, excessive hip flexion, in-toeing were all found to be more prevalent in the whole group, while scissors gait was the less prevalent. There is a greater possibility of crouch gait, rotational mal-alignment, hip rotation in older patients, while children below the age of 0-10years were seen to have equineus and in-toeing predominantly. The major difference that was seen in the gender circle was that females are more likely to develop trendebenburg gait but less likely to have crouch gait.

Conclusion: The result of this study shows that there is a significant difference in gait deviations based on gender, age and sub-type cerebral palsy classification in pediatrics. It is expected that this study will help researchers and clinicians focus their efforts in areas that will enhance the general functioning and the gait efficiency of children suffering from cerebral palsy instead of incorporating excessive treatment options that might have little or no effect on the gait improvement of patients with cerebral palsy. It is also hoped that the result of this study will be useful when counseling patients and parents about the potential ramifications for their children.

Keywords: Age, Gender, Cerebral Palsy, Children, Gait Deviation

\section{Introduction}

Cerebral palsy is a term used to describe a set of neurological conditions that affect movement. It is the most common form of childhood disability [1]. Cerebral palsy is primarily a disorder of movement and posture. It is defined as "umbrella term covering a group of non-progressive, but often changing, motor impairment syndromes secondary to lesion or anomalies of the brain arising in the stages of development" [2]. Cerebral palsy is a childhood condition in which there is a motor disability (palsy) caused by a static non-progressive lesion in the brain (cerebral). Cerebral is characterized by abnormal control of motor function and it may interfere with sensory function and intellectual development.
Cerebral Palsy is considered a neurological disorder caused by a non-progressive brain injury or malformation that occurs while the child's brain is under development. Cerebral Palsy primarily affects body movement and muscle coordination [3-9]. Though Cerebral Palsy can be defined, having Cerebral Palsy does not define the person that has the condition. Cerebral palsy (CP) is the most common motor disability in childhood. This syndrome is the manifestation of intrauterine pathologies, intrapartum complications, and the postnatal sequel, especially among preterm neonates. A double hit model theory is proposed suggesting that an intrauterine condition along with intrapartum or postnatal insult lead to the development of CP. Recent reports demonstrat- 
ed that treatment during the process of preterm birth such as magnesium sulfate and postnatal modalities such as cooling may prevent or reduce the prevalence of this syndrome. Moreover, animal models demonstrated that postnatal treatment with anti-inflammatory drugs coupled with nanoparticles may affect the course of the disease in pups with neuro-inflammation. This review will describe the changes in the epidemiology of this disease, the underlying prenatal mechanisms, and possible treatments that may reduce the prevalence of $\mathrm{CP}$ and alter the course of the disease [4-6]. The causative event has to occur in early childhood, usually defined as less than two years of age.

Exceptional children may be put in various broad categories for purpose of studies and services. Among the broad groups is that which comprises of children with physical impairments. Physical impairments are further considered in three categories, which include: Musculo-skeletal impairments (orthopaedic), Neurological impairments and Chronic health impairments. Neurological impairments refer to physical impairments that result from dysfunction or damage of the nervous system. These include conditions like cerebral palsy, spinal bifida, hydrocephalus and poliomyelitis. Children with cerebral palsy have a condition that is stable and non-progressive, therefore are most ways normal children with special needs. Understanding the medical and anatomical problems in individuals with cerebral palsy is important and also keeping in mind the greater long term goal for such children include, their family, medical care, education and society at large for them to grow and develop to their maximum capabilities. Paying attention to improvement and advancement of the motor effects on ambulatory ability are the most common musculoskeletal problems that the rehabilitation team face when treating children with cerebral palsy. There are only a minority of patients whose motor function is so limited that ambulation is of no concern. From children with the mildest effect of hemiplegia to children with quadriplegia who are just able to achieve standing, lower extremity function for mobility is usually a major concern of parents. The first task in the rehabilitation intervention plan is to individually identify how significant the gait impairment is to a child's whole disability.

Human gait refers to locomotion achieved through the movement of human limbs [7]. Human gait is defined as bipedal, biphasic forward propulsion of center of gravity of the human body, in which there are alternate sinuous movements of different segments of the body with least expenditure of energy. Different gait patterns are characterized by differences in limb-movement patterns, overall velocity, forces, kinetic and potential energy cycles, and changes in the contact with the surface (ground, floor, etc.). Human gaits are the various ways in which a human can move, either naturally or as a result of specialized training [7-30]. Understanding the medical and anatomical problems in individuals with cerebral palsy is important and also keeping in mind the greater long term goal for such children include, their family, medical care, education and society at large for them to grow and develop to their maximum capabilities. Paying attention to improvement and advancement of the motor effects on ambulatory ability are the most common musculoskeletal problems that the rehabilitation team face when treating children with cerebral palsy. There are only a minority of patients whose motor function is so limited that ambulation is of no concern. Gait may mean individual's peculiar pattern of walking which is a repetitive, rhythmical, symmetrical activity. Gait deviations then means pattern(s) of walking is a derangement from the normal. Understanding the medical and anatomical problems in individuals with cerebral palsy is important and also keeping in mind the greater long term goal for such children include, their family, medical care, education and society at large for them to grow and develop to their maximum capabilities.

Impairment like cerebral palsy which restricts locomotion has a lot of negative impact not just to the patient suffering from such impairment but the community of persons around them. A good understanding of the gait pathology is of paramount concern to the rehabilitation team so as to effectively manage the deformity and improve the overall function of the patient. Good rehabilitation plan for such patients gives room for improvement, maintenance or restoration of physical strength, cognition and mobility with the aim of maximizing results, which aims at helping them gain greater independence. In order to fully understand and administer effective management to patients suffering from cerebral palsy, it is important to have a thorough and in depth knowledge of the most prevalent gait deviations in relation to gender, age of the child and cerebral palsy sub-type.

\section{Research Hypothesis}

There will be no significant difference in the gait abnormalities seen in different sub-types of cerebral palsy.

There is no significant relationship between age and gait deviations.

\section{Methodology}

A descriptive study design was adopted to investigate the impact of gender, age and cerebral palsy on the prevalence of specific gait patterns seen on cerebral palsy patient. The information sought out for were; gait deviations, age and gender of the cerebral palsy patients. The study was carried out in two states (Abuja and Benue State) in the middle-belt (North Central) of Nigeria, using Specialist Hospital Gwagwalada, Abuja and N.K.S.T Rehabilitation Hospital, Mkar Benue State. The population studied was cerebral palsy patients that can ambulate and fell within the three most common sub-types of cerebral palsy (Hemiplegics, Di-plegics and Quadriplegics). Stratified random sampling technique was used to put the various variables into sub-groups and ensure effective representation of the sample population. The sample size was cerebral palsy patients currently accessing rehabilitation services at the centers used for the past ten years (January 2005- December 2015) who are within the age range of 4-20 years of age. The data collected was processed, analyzed and presented in frequency tables for clear and easy understanding. 
Results

The table shows reviewed medical folders of one hundred and forty two patient; $43(30 \%)$ were hemiplegic cerebral palsy patients, 78(55\%) were diplegic cerebral palsy patients and $21(15 \%)$ were quadriplegic cerebral palsy patients. The average age of the patients is $8.35 \pm 3.10$ with a range of 4 -20years (Table 1). The table above shows that there $83(58 \% 0$ male and $59(42 \%)$ female patients under review with a mean age of $8.2 \pm 3.16$ (Table 2). Table 3 above shows that stiff knee is the most predominant gait deviation with more prevalence in the diplegic group, but less in the quadriplegic group and scissor gait has the least prevalence. The above shows that hip flexion is the most predominant gait deviation with more prevalence in the group between 16-20years (Table 4).

Table 1: Patients' Demographical Distribution

\begin{tabular}{|c|c|c|c|}
\hline Type of Patient's Cerebral Palsy & Frequency & Percentage (\%) & Age in Yrs (Mean \pm SD) \\
\hline Hemiplegic & 43 & 30 & $8.4 \pm 3.30$ \\
\hline Diplegic & 78 & 55 & $8.05 \pm 3.40$ \\
\hline Quadriplegic & 21 & 15 & $9.30 \pm 2.80$ \\
\hline Total & 142 & 100 & $8.35 \pm 3.10$ \\
\hline
\end{tabular}

Table 2: Gender and Age Distributions of Patients.

\begin{tabular}{|c|c|c|c|}
\hline Gender & Frequency & Percentage (\%) & Age in YRS (Mean \pm SD) \\
\hline Male & 83 & 58 & $3.76 \pm 3.2$ \\
\hline Female & 59 & 42 & $7.80 \pm 3.04$ \\
\hline Total & 142 & 100 & $8.2 \pm 3.16$ \\
\hline
\end{tabular}

Table 3: Gait Deviation Distributions of Patients by Sub-Type.

\begin{tabular}{|c|c|c|c|}
\hline Gait Deviation & Hemiplagic & Diplegic & Quadriplegic \\
\hline Stiff knee & 17 & 26 & 6 \\
\hline In-toeing & 11 & 20 & 5 \\
\hline Crouch & 10 & 15 & 6 \\
\hline Equines & 8 & 30 & 8 \\
\hline Hip flexion & 11 & 16 & 5 \\
\hline Hip adduction & 8 & 15 & 3 \\
\hline Hip rotation & 6 & 0 & 3 \\
\hline Scissoring & 1 & 8 & 1 \\
\hline Trendelenburg gait & 7 & 2 & 3 \\
\hline Rotational mal & 5 & 12 & 0 \\
\hline Calcaneus & 7 & 4 & 2 \\
\hline Out-toeing & 5 & 15.25 & 5.0833 \\
\hline Mean & 8 & 11.054 & 4.944 \\
\hline S.D. & 4 & & \\
\hline
\end{tabular}

Table 4: Prevalence of Gait Deviation Using Age.

\begin{tabular}{|c|c|c|c|c|}
\hline \multirow{2}{*}{ Gait Deviation } & \multicolumn{3}{|c|}{ Age Range } \\
\hline \multirow{2}{*}{ Stiff Knee } & $0-5(\mathrm{n}=31)$ & $6-10(\mathrm{n}=79)$ & $11-15(\mathrm{n}=29)$ & $16-20(\mathrm{n}=31)$ \\
\cline { 2 - 5 } & $15 \%$ & $27 \%$ & $10 \%$ & $0 \%$ \\
\hline In-toeing & $29 \%$ & $7 \%$ & $20 \%$ & $0 \%$ \\
\hline Crouch & $3 \%$ & $7 \%$ & $1 \%$ & $0 \%$ \\
\hline Equineus & $24 \%$ & $14 \%$ & $11 \%$ & $50 \%$ \\
\hline Hip flexion & $13 \%$ & $18 \%$ & $11 \%$ & $25 \%$ \\
\hline Hip adduction & $6 \%$ & $10 \%$ & $11 \%$ & $25 \%$ \\
\hline Hip rotation & $1 \%$ & $3 \%$ & $4 \%$ & \\
\hline Scissors & $0 \%$ & $2 \%$ & & $0 \%$ \\
\hline
\end{tabular}




\begin{tabular}{|c|c|c|c|c|}
\hline Trendelenburg & $5 \%$ & $10 \%$ & $2 \%$ & $0 \%$ \\
\hline Rotational malalignment & $0 \%$ & $0 \%$ & $10 \%$ & $0 \%$ \\
\hline Calcaneus & $2 \%$ & $2 \%$ & $10 \%$ & $0 \%$ \\
\hline Out-toeing & $0 \%$ & $0 \%$ & $8 \%$ & $0 \%$ \\
\hline Total & $100 \%$ & $100 \%$ & $100 \%$ & $100 \%$ \\
\hline
\end{tabular}

Test of Hypothesis

\section{Hypothesis 1}

There will be no significant difference in the gait abnormalities seen in the different sub-types of cerebral palsy.

I. Test statistic: Analysis of Variance (ANOVA)

II. Observation: $\mathrm{p}=0.006$

III. Level of significance: $\mathrm{p}<0.05$

IV. Inference: The statistical analysis showed that there is a significant difference in the gait abnormalities seen in different sub-types of cerebral palsy.

V. Verdict: the null hypothesis is hereby rejected.

\section{Hypothesis 2}

There is no significant relationship between age and gait deviations in cerebral palsy patients.

i. Test statistics: Regression

ii. Observation: $p=0.001$

iii. Level of significance: $p<0.05$

iv. Inference: the statistical analysis showed that age had significant relationship with gait deviations of the study population.

v. Verdict: the null hypothesis is hereby rejected.

\section{Discussion}

The result obtained from this study showed that the most children with cerebral palsy have a lot gait deviations which corresponds to the findings of Stephane A et al. [31]. Although, from an oral interview with a physiotherapist at the N.K.S.T rehabilitation Center, it was deduced that ankle-foot deformities were more prevalent among cerebral palsy children, but the result showed stiff knee was the most predominant. The next prevailing gait deviation is hip flexion, followed by in-toeing, crouch and equines. The result also showed that female cerebral palsy children are more likely to have trendelenburg gait than their male counterpart. The reason for this is yet to be investigated but can be suggested to be as result of the pelvic bone shape difference between male and female. It also showed that patients below 10years of age are more likely to have equineus, in-toeing and stiff knee gait abnormalities but less of crouch, hip rotation, rotational mal-alignment, calcaneus and hip flexion, while patients above 10years of age are more likely to develop calcaneus, out-toeing, rotational mal-alignment and hip rotation. The result analysis showed that; there is a significant difference between the gait abnormalities and various sub-types of cerebral palsy, $\mathrm{p}<0.05$ and there is also a significant relationship between age and gait deviations in cerebral palsy patients, $\mathrm{p}<0.05$.

\section{Conclusion}

This research opined that there is a significant difference in gait deviation of cerebral palsy patients based on age and subtype of cerebral palsy in children. Gait deviations like; calcaneus, crouch, rotational mal-alignment, hip flexion and internal hip rotation were more prevalent in children below 10years of age. The study also holds that cerebral palsy patients are faced with a lot of health challenges which is in line with work of Sachs B, et al. [26]. It was also deduced from the study that stiff knee is more prevalent in the diplegic group, with least prevalence in the quadriplegic group. This research study is hope to be relevant to medical rehabilitation professionals as it provides therein useful information to health care givers in management of cerebral palsy patients and also researchers in this field of study.

\section{References}

1. Karen G (2017) Medical News Today.

2. Mutch L, Alberman E, Hagberg B, Kodama K, Perat MV (1992) Cerebral palsy epidemiology: where are we going? Dev Med Child Neurol 34(6): 547-551.

3. Ndurumo M (2002) Exceptional children. Developmental consequences and intervention. Nairobi. Longman Kenya Ltd 2002.

4. Stavsky M, Mor O, Mastrolia SA, Greenbaum S, Than NG, et al. (2017) Cerebral palsy- Trends in Epidemiology and Recent Development in Prenatal Mechanism, Treatment and Prevention. Front Pediatr 5: 21.

5. Blair E (2010) Epidemiology of the cerebral palsies. Orthop Clin North Am 41(4): 441-445.

6. Miller G, Clark GD (1998) The cerebral palsies: Causes, Consequences, and management. Boston: Butterworth- Heinemann, USA.

7. (2018) Wikipedia.

8. Kenneth AS (2018) My child at cerebral palsy.org.

9. Badawi N, Watson L, Petterson B (1998) What constitutes cerebral palsy? Dev Med Child Neuro 40(8): 520-527.

10. Burja S, Semeciglenecki P, Gajsek M, Hajidinjak D, Levanic A, et al. (2004) Epidemiological study of cerebral palsy in the Maribor region. Wien Klin Wochenschr 166(2): 39-43.

11. Dolk H, Parkes J, Hill N (2006) trends in the prevalence of cerebral palsy in Northern Ireland. Dev Med Child Neurol 48(6): 406-412.

12. Drummond PM, Clover AF (2002) Analysis by gestational age of cerebral palsy in singleton births in north-east England 1970-1994. Paediatr Perinat Epidemiol 16(2):172-180.

13. Gowers WR (1888) A manual of Disease of the Nervous System. Churchill London 2: 380-428. 
14. Himmelmann K, Beckung E, Hagberg G, Uvebrant P (2006) Gross and fine motor function and accompanying impairments in cerebral palsy. Dev Med Neurol 48(6): 417-423.

15. Jurcisin G (1968) Dynamics of the Doman-Delacato creeping-crawling technique for the brain-damaged child. Am correct Ther J 22(5):161164

16. Kuban KCK, Leviton A (1994) Cerebral Palsy. N Engl Med 330(3): 188195.

17. Lindenberg R, Freytag E (1969) Morphology of brain lesions from blunt trauma in early infancy. Arch Pathol 87(3): 298-305.

18. MacLennan A (1999) A template for defining a casual relation between acute intrapartum events and cerebral palsy: international consensus statement. BMJ 319(7216): 1054-1059.

19. Mahoney WJ, D Souza BJ, Haller JA, Rogers MC, Epstein MH, et al (1983) Long -term outcome of children with severe head trauma and prolong coma. Pediatrics 71(5): 756-762.

20. Minear WL (1956) A classification of cerebal palsy. Pediatrics 5: 841 852

21. Mutch L, Alberman E, Hagberg B, Kodama K, Perat MV (1992) Cerebral palsy epidemiology: where are we now and where are we going? Dev Med Child Neurol 34(6): 547-551.

22. O Reilly DE, Walentynowicz JE (1981) Etiological factors in cerebral palsy: an historical review. Dev Med Child Neurol 23(5): 633-642.
23. Perlstein MA (1952) Infantile cerebral palsy. Classification and clinical correlations. J Am Med Assoc 149(1): 30-34.

24. Rogers B (2004) Feeding method and health outcomes of children with cerebral palsy. J Pediatr 145(2 Suppl): S28-32.

25. Russell CL, Kennedy F (eds). A Textbook of Medicine, ( $4^{\text {th }}$ edn). W B Saunders Company, Philadephia USA. Pp. 1371.

26. Sachs B, Peterson F (1998) A study of cerebral palsies of early life, based upon an analysis of one hundred and forty cases. J Med Genet 35: 497-5021.

27. Takakwaki k (2017) Functional Neuroanatomy for postures and gait control. J Mov Disord 10(1):1-17.

28. Cunnigham CB, Schilling N, Anders C, Carrier DR (2010) The influence of foot posture on the cost transport in humans. J Exp Biol 213(5): 790797.

29. Thach WT, Bastian AJ (2004) Role of the cerebellum in the control and adaptation of gait in health and disease. Prog Brain Res 143: 353-366.

30. Ackermann M, Van den B, Antonie J (2012) Predictive simulation of gait at low gravity reveals skipping as the preferred locomotion strategy. Biomech 45(7): 1293-1298.

31. Stephane A, Geraldo D, Alice B (2016) Gait analysis in children with cerebral palsy. EFFORT Open Rev 1(12): 448-460.

Your next submission with Juniper Publishers will reach you the below assets

- Quality Editorial service

- Swift Peer Review

- Reprints availability

- E-prints Service

- Manuscript Podcast for convenient understanding

- Global attainment for your research

- Manuscript accessibility in different formats

(Pdf, E-pub, Full Text, Audio)

- Unceasing customer service

Track the below URL for one-step submission https://juniperpublishers.com/online-submission.php 